\title{
Highly Porous Carbon Materials from Biomass by Chemical and Carbonization Method: A Comparison Study
}

\author{
Wan Nor Roslam Wan Isahak, Mohamed Wahab Mahamed Hisham, and Mohd Ambar Yarmo \\ Low Carbon Economy (LCE) Research Group, School of Chemical Sciences and Food Technology, Faculty of Science and Technology, \\ Universiti Kebangsaan Malaysia (UKM), 43600 UKM Bangi, Selangor, Malaysia
}

Correspondence should be addressed to Wan Nor Roslam Wan Isahak; wannorroslam@yahoo.com

Received 19 June 2012; Accepted 11 August 2012

Academic Editor: Jean-Luc Blin

Copyright (C) 2013 Wan Nor Roslam Wan Isahak et al. This is an open access article distributed under the Creative Commons Attribution License, which permits unrestricted use, distribution, and reproduction in any medium, provided the original work is properly cited.

\begin{abstract}
Porous carbon obtained by dehydrating agent, concentrated sulfuric acid $\left(\mathrm{H}_{2} \mathrm{SO}_{4}\right)$, from biomass containing high cellulose (filter paper (FP), bamboo waste, and empty fruit bunches (EFB)) shows very high surface area and better thermal behavior. At room temperature (without heating), treatment of $\mathrm{H}_{2} \mathrm{SO}_{4}$ removed all the water molecules in the biomass and left the porous carbon without emitting any gaseous byproducts. Brunauer-Emmett-Teller (BET) surface analysis has shown that bamboo-based carbon has good properties with higher surface area $\left(507.8 \mathrm{~m}^{2} / \mathrm{g}\right)$, micropore area $\left(393.3 \mathrm{~m}^{2} / \mathrm{g}\right)$, and better thermal behavior $($ compared to FP and EFB) without any activation or treatment process. By acid treatment of biomass, it was shown that higher carbon composition obtained from FP (85.30\%), bamboo (77.72\%), and EFB (76.55\%) is compared to carbon from carbonization process. Under optimal sulfuric acid (20 wt.\%) uses, high carbon yield has been achieved for FP (47.85 wt.\%), bamboo (62.4 wt.\%), and EFB (55.4 wt.\%).
\end{abstract}

\section{Introduction}

Biomass is a renewable resource that provided steady and abundant supply of waste materials such as empty fruit bunch (EFB), wood chips, and bamboo. These waste materials are traditionally used for the production of charcoals and carbon materials including the porous structure activated carbons and microporous amorphous carbon materials that are widely used as adsorbents [1-3], materials for the separation of gases [4-7], and catalyst support $[8,9]$. On the other hand, there is growing interest in the development of new carbon materials produced directly from plant materials to make carbon composites [10], carbon nanotubes (CNTs) $[11,12]$, and environmental adsorbents $[13,14]$.

Carbon materials with a developed porous structure such as activated carbon, coke, and charcoal are produced by pyrolysis or carbonization of the biomass followed by physical and chemical activation. In carbonization of wood to produce charcoal, other side products, namely, carbon monoxide (CO), methane, and water are obtained [10]. Carbonization process of wood at about $400^{\circ} \mathrm{C}$ could yield
$19 \%$ charcoal by weight (\%). Considering of biomass and charcoal compositions, it is estimated theoretical yield of high-quality charcoal could be produced as much as 44 to $55 \%$. Tippayawong et al. [15] reported that the carbonization of wood in a small natural draft carbonizer gives charcoal yield of 33-38\%. In 1990s, Mok et al. (1992) have reported the charcoal production by using sealed reactor. The biomass bamboo type Eucalyptus gummifera was pyrolyzed at typical condition to obtain about $48 \%$ of charcoal [16]. In addition, different species of biomass feedstock would influence the charcoal production and quality. Higher charcoal yields were obtained from biomass species that contains high lignin or low hemicelluloses content.

Generally, the carbonization of biomass would lead to produce charcoal as well as gaseous products such as $\mathrm{CO}$, $\mathrm{CH}_{4}$, and water as shown in (1) [10]. This process seems unfriendly approach for charcoal synthesis in terms of higher greenhouse gas $(\mathrm{CHG})$ emissions. In this paper, we present the properties of carbon materials produced by dehydration method (chemical method) based on high cellulose content sources expressed by (2). Theoretically, by dehydration 

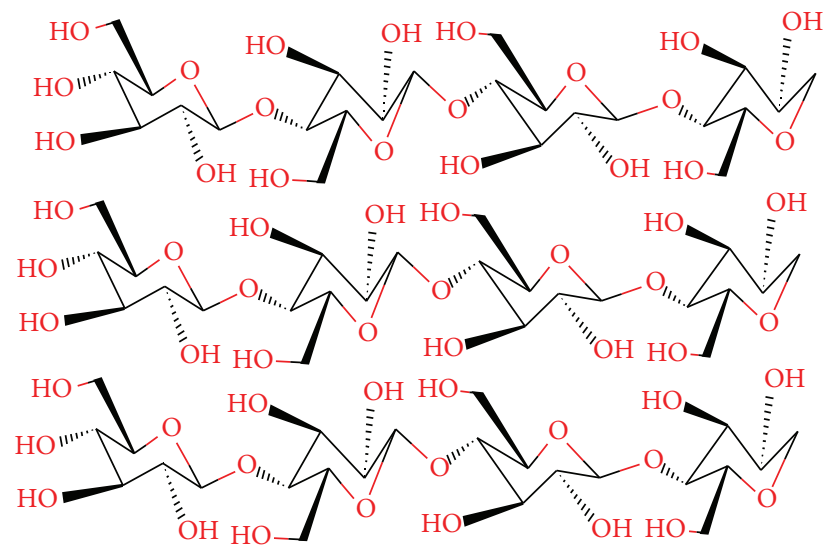

Dehydration

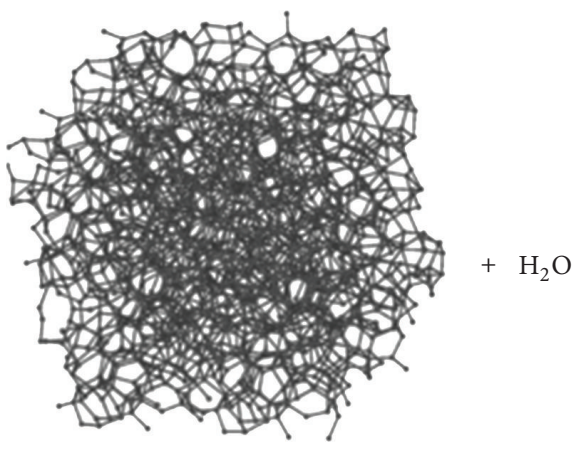

Biomass containing high cellulose

Porous carbon

FIGURE 1: Transformation of biomass containing high cellulose into porous carbon by dehydration (chemical method).

process (chemical method) of cellulose, 5 moles of water in cellulose structures can be removed by concentrated sulfuric acid to form porous carbon. Figure 1 illustrated the dehydration of cellulose into porous carbon. This is a green route to synthesis of high content of carbon without any GHG emissions which only produced water as a byproduct as would be explained in this paper:

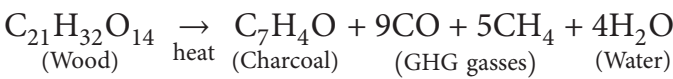

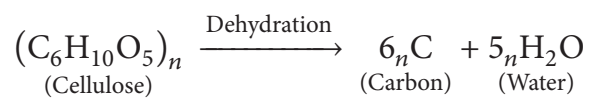

In this work, a comparison study was drawn based on the types of biomass using carbonization and dehydration process (chemical) to produce porous carbon. To find better solution to environmental issues, the dehydration process was applied as an alternative technique to synthesis of highyield and -quality carbon at room temperature (without heating) which is a very low-cost route, easy in handling, and zero emission of GHG. This study was focusing on three selected high cellulose content of biomass samples, namely, bamboo, EFB, and filter paper (FP). complete physical characteristics and properties of synthesized carbon were also studied throughout this paper.

\section{Experimental and Analysis Methods}

2.1. Sample Preparation. Three high cellulose contents or biomass samples, namely, bamboo, FP (Whatman no. 1), and EFB were selected as potential sources. The EFB and bamboo were obtained from local palm oil farm and furniture factory in Kelantan, Malaysia, respectively. These collected samples were washed thoroughly with distilled water to remove adhering soil and dust and dried at $110^{\circ} \mathrm{C}$ overnight. The FP (Whatman no. 1) was purchased from GE Healthcare Limited, UK. Analytical grade sulfuric acid (98 wt.\%) was supplied by Fisher Scientific Limited, UK.

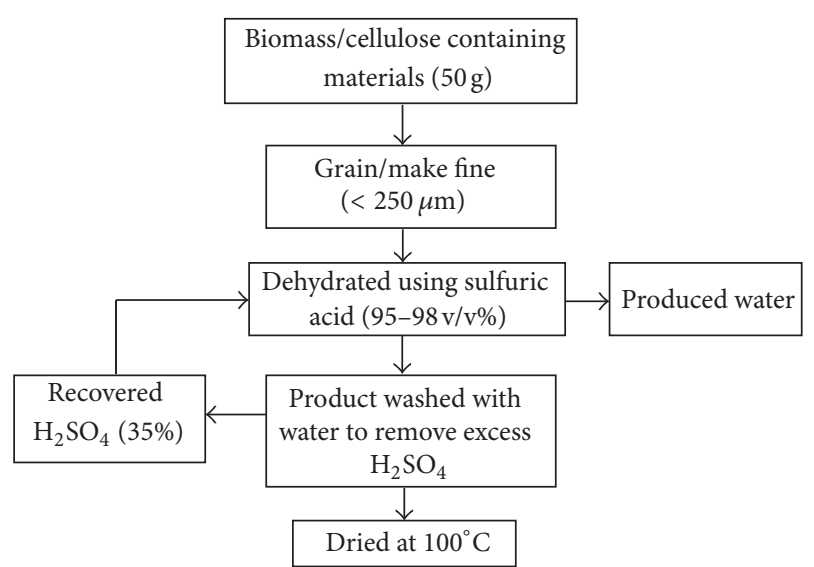

FIGURE 2: Flowchart for carbon production from high cellulose content materials.

\subsection{Preparation of Porous Carbon}

2.2.1. Carbonization/Heating Method. The high cellulose content feedstock (Whatman FP: type no. 1, EFB, and bamboo) were dried at $110^{\circ} \mathrm{C}$ for $12 \mathrm{~h}$ [17]. Then, samples was carbonized in nitrogen at $500^{\circ} \mathrm{C}$ for $2 \mathrm{~h}$ by a ramping temperature of $6^{\circ} \mathrm{C} / \mathrm{min}$.

2.2.2. Dehydration Process. $50 \mathrm{~g}$ of high cellulose content feedstock (bamboo, FP, and EFB) were putted in a proper quartz column. Then, $15 \mathrm{~mL}$ of sulfuric acid $\left(\mathrm{H}_{2} \mathrm{SO}_{4}\right)$ was flowing through the column. The fast reaction was performed at room temperature. The flowchart of this work was summarized in Figure 2.

2.3. Physical and Chemical Characterization. Nitrogen adsorption at $77 \mathrm{~K}$ (liquid nitrogen) was conducted using a Micromeritics ASAP 2010 instrument to obtain the adsorption isotherm of each sample. The Brunauer-EmmettTeller (BET) surface area, micropore volume, and micropore 


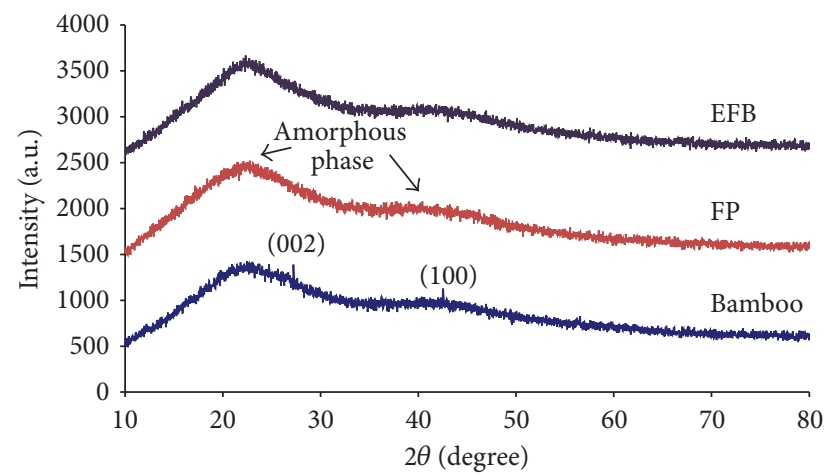

FIGURE 3: XRD diffractogram of carbon (bamboo, FP, and EFB) synthesized by dehydration process.

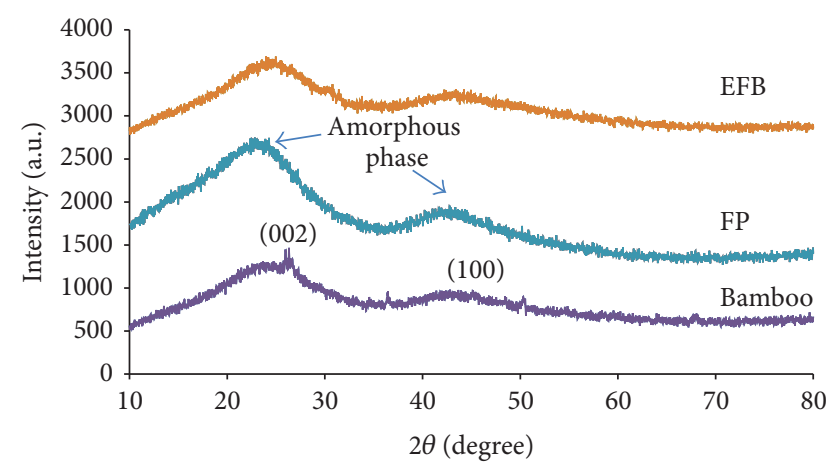

Figure 4: XRD diffractogram of carbon (bamboo, FP, and EFB) synthesized by carbonization process.

area were calculated from the isotherms. Before running analysis, the samples were degassed at $350^{\circ} \mathrm{C}$ for 6 hours. The crystallinity analyses of the samples were performed using Bruker DB-Advance X-ray diffractometer (XRD), Germany. The analyses were employing $\mathrm{Cu} K \alpha$ radiation at $2 \theta$ ranging from $10^{\circ}$ to $80^{\circ}$ of $1 \mathrm{~g}$ sample. The infrared spectra of the carbon samples were recorded on a spectrum 400, FT-IR/FTNIR spectrometer (Perkin Elmer, UK) using the attenuated total reflection (ATR) method for sample preparation technique. A mass of $0.5 \mathrm{mg}$ of carbon sample was used for all tests. Elemental analyses were carried out using a Fison EA $1108 \mathrm{C}, \mathrm{H}, \mathrm{N}, \mathrm{O}$ analyzer. The surface micrograph of porous carbon was studied using field emission scanning electron microscope (FESEM). The oxidative mass loss of the samples was analyzed in air using dynamic thermal gravimetric analysis (TGA) with a simultaneous TGA-DTG system (Model: Mettler Toledo). To reduce the influence of the sample quantity on the analyses, $5( \pm 0.2) \mathrm{mg}$ of each sample was used in each analysis and a constant air flow of $50.0 \mathrm{~mL} \mathrm{~min}^{-1}$ was maintained throughout the entire process. To minimize possible differences in the moisture content between samples, all TGA samples were equilibrated at $50^{\circ} \mathrm{C}$ for $5 \mathrm{~min}$ before heated to $700^{\circ} \mathrm{C}$ at a ramping rate of $5^{\circ} \mathrm{C} \mathrm{min}^{-1}$.
TABLE 1: Surface properties of carbon from different biomass.

\begin{tabular}{|c|c|c|c|c|c|c|}
\hline \multirow{2}{*}{$\begin{array}{l}\text { Physical } \\
\text { properties }\end{array}$} & \multicolumn{3}{|c|}{ Dehydration method } & \multicolumn{3}{|c|}{ Carbonization method } \\
\hline & FP & EFB & Bamboo & FP & $\mathrm{EFB}$ & Bamboo \\
\hline $\begin{array}{l}\text { Surface area } \\
\left(\mathrm{m}^{2} / \mathrm{g}\right)\end{array}$ & 376.93 & 446.27 & 507.76 & 153.00 & 263.24 & 293.46 \\
\hline $\begin{array}{l}\text { Micropore area } \\
\left(\mathrm{m}^{2} / \mathrm{g}\right)\end{array}$ & 270.28 & 359.54 & 393.29 & 115.00 & 223.42 & 234.72 \\
\hline $\begin{array}{l}\text { Micropore } \\
\text { volume } \\
\left(\mathrm{cm}^{3} / \mathrm{g}\right)\end{array}$ & 0.17 & 0.19 & 0.21 & 0.06 & 0.10 & 0.12 \\
\hline
\end{tabular}

TABLE 2: Elemental composition (wt.\%) in various biomass.

\begin{tabular}{lcccc}
\hline Biomass source & C & H & O & N \\
\hline Filter paper (wood-based) & 40.83 & 6.79 & 42.14 & 10.24 \\
Bamboo & 36.32 & 3.88 & 48.74 & 11.06 \\
Empty fruit bunch (EFB) & 35.65 & 3.97 & 48.03 & 12.35 \\
\hline
\end{tabular}

\section{Results and Discussion}

3.1. Surface and Porosity Studies. Surface analysis by BET showed that the carbon synthesized by dehydration method had better surface properties in terms of surface area and micropore area compared to carbonization method. It is clearly shown that the carbon prepared by dehydration using sulfuric acid is higher in surface area and porosity. This could be a good indication of the sulfuric acid functioning as a water removal which not much breaks cellulose walls. Bamboo feedstock gave better properties of carbon with higher surface area $\left(507.8 \mathrm{~m}^{2} / \mathrm{g}\right)$, micropore area $\left(393.3 \mathrm{~m}^{2} / \mathrm{g}\right)$ and micropore volume $\left(0.21 \mathrm{~cm}^{3} / \mathrm{g}\right)$. FP has showed lower surface area $\left(376.9 \mathrm{~m}^{2} / \mathrm{g}\right)$ and porosity $\left(270.28 \mathrm{~m}^{2} / \mathrm{g}\right)$ as summarized in Table 1, without any activation and treatment process. It indicates that the bamboo type of biomass is composed of high content of ash component compared to FP and EFB sources. High-ash content biomass functions as a precursor to form high porosity carbon materials $[18,19]$. In further work, this carbon (from dehydration or carbonization) can be activated by chemical and physical methods to increase their surface area up to $2500 \mathrm{~m}^{2} / \mathrm{g}$. In literature, Zhang et al. were reported the synthesis of very high-porosity carbonderived rice straw and corn stalks after chemical activation with potassium hydroxide $(\mathrm{KOH})[20,21]$.

3.2. Crystallinity. The XRD analyses show that the carbon synthesized from bamboo, EFB, and FP were clearly formed in an amorphous state. The crystalline phase of high content cellulose is broken by sulfuric acid to form amorphous carbon. There are two obvious peaks represent amorphous carbon at $2 \theta$ value of $22.4^{\circ}$ and $42.3^{\circ}$ as shown in Figure 3. The appearance of sulfuric acid together with high cellulose content feedstock could pick up the water molecule from samples to form high purity and porosity carbon. No any significant difference between EFB, FP, and bamboo synthesized by dehydration and carbonization process (Figure 4). XRD pattern matches well to previously reported pattern for 
TABLE 3: Elemental composition (value in wt.\%) in biomass-based carbon.

\begin{tabular}{lcccccccc}
\hline \multirow{2}{*}{ Elements } & \multicolumn{3}{c}{ Carbonization method } & \multicolumn{3}{c}{ Dehydration method } & \multicolumn{2}{c}{ Commercial charcoal (CC) } \\
& FP & Bamboo & EFB & FP & Bamboo & EFB & 73.60 & $60-75$ \\
C & 84.2 & 74.58 & 71.43 & 85.30 & 77.72 & 76.55 & 4.82 & $6.0-5.8$ \\
$\mathrm{H}$ & 3.62 & 2.26 & 2.54 & 4.46 & 3.82 & 3.17 & 1.4 & $34-17$ \\
$\mathrm{~N}$ & 0.31 & 0.82 & 1.47 & 0.21 & 1.10 & 1.1 & 20.18 & $45-65$ \\
Volatile elements & 11.87 & 22.34 & 24.56 & 9.89 & 17.36 & 19.18 & \\
\hline
\end{tabular}

TABLE 4: Carbon yields from acid treatment (dehydration) of high cellulose content.

\begin{tabular}{lccc}
\hline \multirow{2}{*}{ Quantity of $\mathrm{H}_{2} \mathrm{SO}_{4}$ uses (wt.\%) } & \multicolumn{3}{c}{ Carbon yield (wt.\%) } \\
& $\mathrm{FP}$ & Bamboo & EFB \\
\hline 5 & 32.5 & 41.0 & 35.6 \\
10 & 42.3 & 48.5 & 43.2 \\
15 & 44.6 & 56.4 & 45.5 \\
20 & 47.9 & 62.4 & 55.4 \\
\hline
\end{tabular}

nongraphitic carbon [22]. However, little amount of graphite phase is detected in bamboo-based carbon approximate at $27.2^{\circ}$ and $44.5^{\circ}$, respectively, which assigned to the planes of graphite (002) and (100). It was difficult to obtain fully graphite of solid carbon at low carbonization temperatures (such as $500^{\circ} \mathrm{C}$ ).

3.3. Fourier Transform Infrared Spectroscopy (FT-IR) Study. FT-IR analysis of cellulose-rich samples exhibits a typical carbohydrate-type spectrum. The peaks at $900 \mathrm{~cm}^{-1}$ to $1200 \mathrm{~cm}^{-1}$ are associated with absorption by $\mathrm{OH}, \mathrm{CH}$, $\mathrm{C}-\mathrm{OH}$, and $\mathrm{CH}_{2}$ groups in the glycosyl units of cellulose (untreated samples) (Figures 5(a), 5(b), and 5(c)). The bands at $875-750 \mathrm{~cm}^{-1}$ are assigned to aromatic $\mathrm{C}-\mathrm{H}$ group out-ofplane bending vibrations.

The FT-IR spectrum also exhibits bands at 3340 and $2900 \mathrm{~cm}^{-1}$ representing stretching vibrations of $\mathrm{O}-\mathrm{H}$ (hydroxyl or carboxyl) and aliphatic $\mathrm{C}-\mathrm{H}$, respectively, whereas the bands at 1725 and $1630 \mathrm{~cm}^{-1}$ are attributed to $\mathrm{C}=\mathrm{O}$ and $\mathrm{C}=\mathrm{C}$ vibrations, respectively, which supporting the existence of aromatization of sugars structure. After heating at $500^{\circ} \mathrm{C}$ for 2 hours, it was shown that all of these peaks disappeared due to the complete decomposition of the glycosidic structures. In fact, the identified peaks at $3340 \mathrm{~cm}^{-1}(\mathrm{O}-\mathrm{H}), 2900 \mathrm{~cm}^{-1}(\mathrm{C}-\mathrm{H}), 1720 \mathrm{~cm}^{-1}(\mathrm{C}=\mathrm{O})$, and $1630 \mathrm{~cm}^{-1}(\mathrm{C}=\mathrm{C})$ were diminished during carbonization and dehydration processes.

3.4. Elemental Composition (wt.\%) by CHNSO Analyzer. The high cellulose content samples (filter paper, EFB, and bamboo) are composed in the ranging of 35.65-40.83 wt.\% (C), 3.88-6.79 wt.\% (H), 42.14-48.74 wt.\% (O), and 10.24-12.35 wt.\% (N) as shown in Table 2. All these samples consist above $50 \%$ of cellulose and the rest were hemicelluloses and lignin.

The elemental analysis of porous carbon prepared by carbonization and dehydration processes and, commercial charcoal (CC) is displayed in Table 3. The carbon prepared by dehydration process gives slightly similar carbon content (wt.\%) compared to carbon from carbonization process. The $\mathrm{H}$ and $\mathrm{N}$ content is almost the same for different carbon while, content of volatile elements of carbon prepared by carbonization process is slightly higher than dehydration process. However, the lower value of this element can be achieved by employing the higher carbonization temperature above $500^{\circ} \mathrm{C}$. The carbon prepared from dehydration have better properties and carbon content (wt.\%) compared to bulk coal and commercial charcoal from market as well as carbon synthesized by carbonization method.

3.5. Surface Micrographs. From FESEM micrographs below (in Figures 6(a) and 6(b)), it was clearly shown that the carbonization and dehydration methods successfully produce highly porous carbon (based on bamboo biomass) without any heating and activation. The micrograph of carbon surface from dehydration method was not that dissimilar to the carbon produced by carbonization method. This means that dehydration by using sulfuric acid can be performed as well as heating (carbonization) at above $500^{\circ} \mathrm{C}$.

3.6. Thermal Behavior by TGA. Significant difference in oxidative mass change is observed between the dehydration and carbonization processes of high cellulose content samples. For carbonized carbon from EFB, it is oxidized easier than carbon from bamboo and FP sources. At $450^{\circ} \mathrm{C}$, EFB carbon mass is reduced $5 \mathrm{wt} . \%$ and FP carbon was starting decomposition at the same conditions. The bamboo-based carbon gives higher mass residue of $85 \mathrm{wt} . \%$ at thermal degradation temperature of $700^{\circ} \mathrm{C}$ as shown in Figure 7 .

The comparatively large difference is also observed in the carbon samples prepared by dehydration process. Bamboo carbon has shown good properties of oxidative behavior in terms of higher residue balance of $87 \mathrm{wt} \%$ (Figure 8 ). It is indicated that bamboo has higher content of lignin compared to FP and EFB. The lignin compound can be functioned for increasing thermal stabilization of carbon [17].

3.7. Effectiveness of Dehydration Process. Comparative studies show that different quantities of sulfuric acid $\left(\mathrm{H}_{2} \mathrm{SO}_{4}\right)$ are used for dehydration process of the selected raw materials. The quantity 20 wt.\% of $\mathrm{H}_{2} \mathrm{SO}_{4}$ shows the significant effects on carbon yield (wt.\%) for different source high cellulose contents (Table 4). Bamboo source gives higher carbon yield of 62.4 wt.\% compared to EFB (55.4 wt.\%) and FP (47.9 wt.\%). The high-level content of ash in bamboo relatively affects 


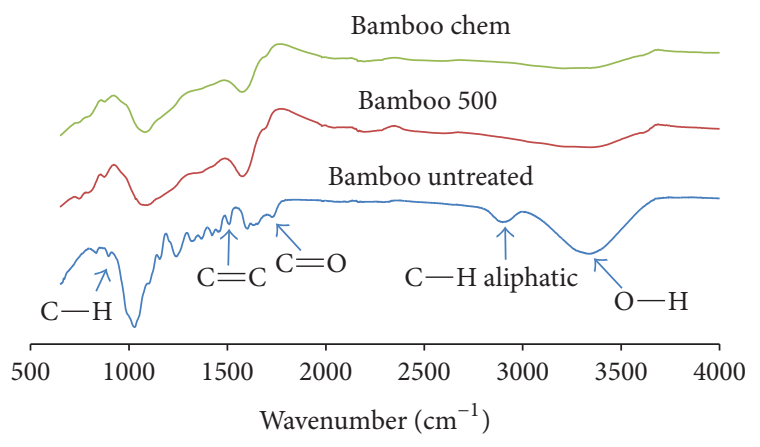

(a)

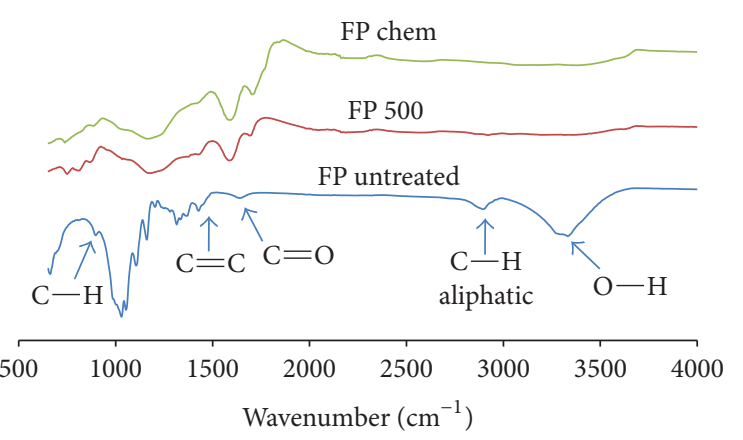

(b)

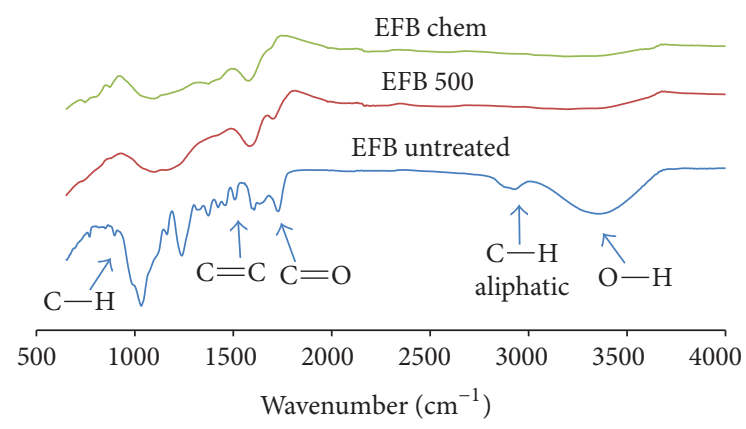

(c)

FIGURE 5: FT-IR spectrums of (a) bamboo, (b) FP, and (c) EFB samples (untreated, heated at $500^{\circ} \mathrm{C}$, and chemical dehydration).

the carbon yield from biomass pyrolysis process [19]. This parameter can stimulate dehydration process of biomass into high content of carbon which has wide potential uses as an absorbent, catalyst, and solid fuel.

\section{Summary}

These studies show that the porous carbon with better surface area and thermal stability can be produced from filter paper (FP), empty fruit bunches (EFB), and bamboo by dehydration process using concentrated sulfuric acid. It is also shown that better properties and characterization of carbon could be obtained compare with carbonization process. The carbon obtained from these processes exhibited high specific surface

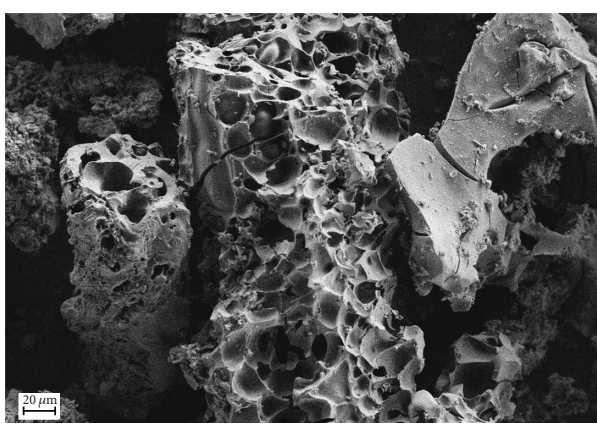

(a)

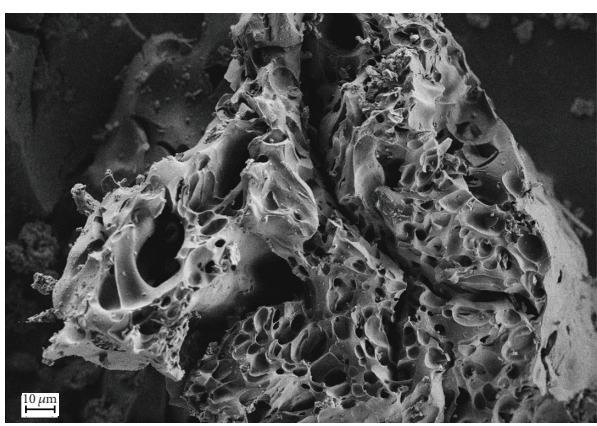

(b)

FIGURE 6: FESEM micrograph for bamboo biomass: (a) carbonization and (b) dehydration (chemical) routes.

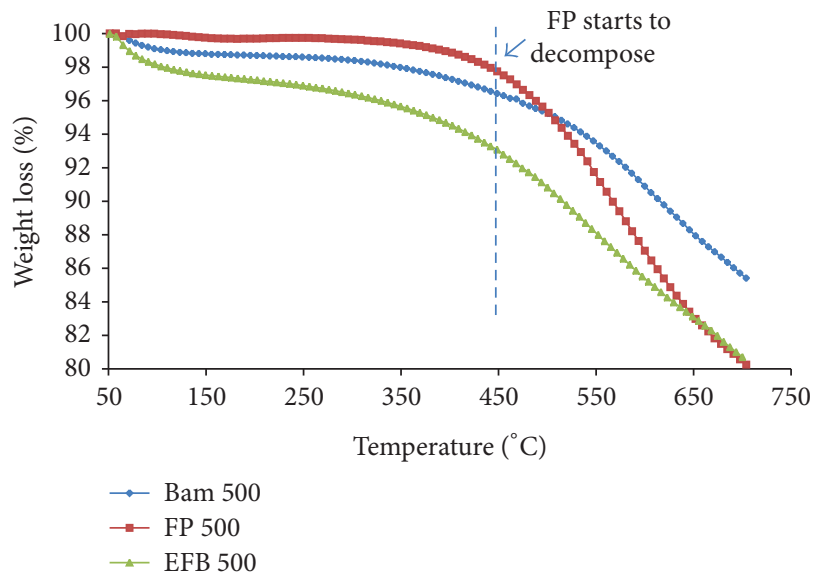

Figure 7: TGA analyses for bamboo, FP, and EFB carbons from carbonization process.

area and porosity without emissions of greenhouse gasses (GHG) such as $\mathrm{CO}_{2}$. This process is expected to stimulate directly decreasing global warming effect, in other way, contributing easier, and green route to produce highly porous carbon materials from biomass waste.

\section{Acknowledgments}

The authors wish to thank Universiti Kebangsaan Malaysia (UKM) for funding this project under Research Grant no. UKM-GUP-BTK-14-306/Dana Lonjakan, Long-Term 


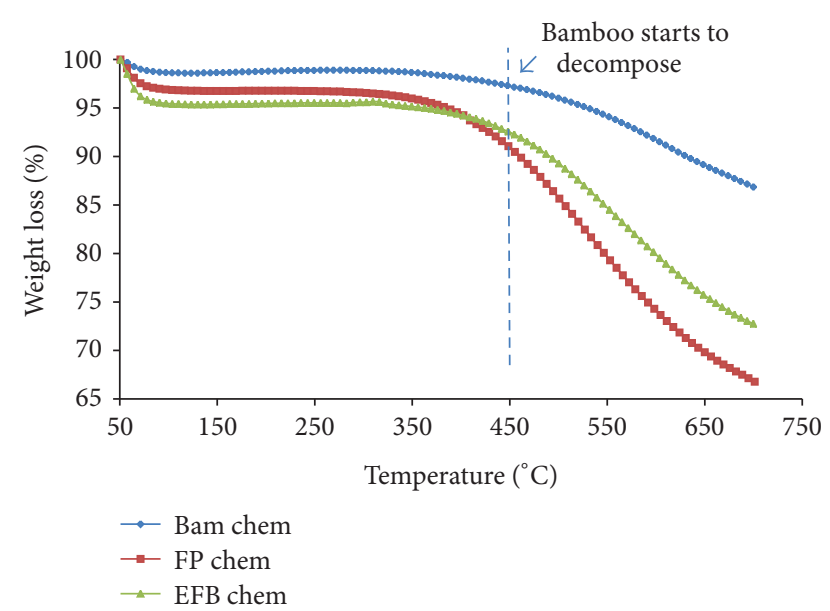

FIGURE 8: TGA analyses for bamboo, FP, and EFB carbons from dehydration process.

Research Grant (LRGS/BU/2011/USM-UKM/PG/02) from Ministry of Higher Education (MOHE) Malaysia, and Centre of Research and Innovation Management (CRIM), UKM for the instruments.

\section{References}

[1] Z. Hu and M. P. Srinivasan, "Mesoporous high-surface-area activated carbon," Microporous and Mesoporous Materials, vol. 43, no. 3, pp. 267-275, 2001.

[2] H. Marsh, D. Crawford, T. M. O'Grady, and A. Wennerberg, "Carbons of high surface area. A study by adsorption and high resolution electron microscopy," Carbon, vol. 20, no. 5, pp. 419-426, 1982.

[3] R. L. Tseng and S. K. Tseng, "Pore structure and adsorption performance of the $\mathrm{KOH}$-activated carbons prepared from corncob," Journal of Colloid and Interface Science, vol. 287, no. 2, pp. 428-437, 2005.

[4] S. Sircar, T. C. Golden, and M. B. Rao, "Activated carbon for gas separation and storage," Carbon, vol. 34, no. 1, pp. 1-12, 1996.

[5] M. M. Mohamed, "Acid dye removal: comparison of surfactantmodified mesoporous FSM-16 with activated carbon derived from rice husk," Journal of Colloid and Interface Science, vol. 272, no. 1, pp. 28-34, 2004.

[6] P. Nowicki, H. Wachowska, and R. Pietrzak, "Active carbons prepared by chemical activation of plum stones and their application in removal of $\mathrm{NO}_{2}$," Journal of Hazardous Materials, vol. 181, no. 1-3, pp. 1088-1094, 2010.

[7] J. Li, N. Kobayashi, and Y. Hu, "The activated coke preparation for $\mathrm{SO}_{2}$ adsorption by using flue gas from coal power plant," Chemical Engineering and Processing, vol. 47, no. 1, pp. 118-127, 2008.

[8] G. H. Oh and C. R. Park, "Preparation and characteristics of rice-straw-based porous carbons with high adsorption capacity," Fuel, vol. 81, no. 3, pp. 327-336, 2002.

[9] I. A. W. Tan, A. L. Ahmad, and B. H. Hameed, "Optimization of preparation conditions for activated carbons from coconut husk using response surface methodology," Chemical Engineering Journal, vol. 137, no. 3, pp. 462-470, 2008.
[10] C. E. Byrne and D. C. Nagle, "Carbonization of wood for advanced materials applications," Carbon, vol. 35, no. 2, pp. 259-266, 1997.

[11] B. Goodell, X. Xie, Y. Qian, G. Daniel, M. Peterson, and J. Jellison, "Carbon nanotubes produced from natural cellulosic materials," Journal of Nanoscience and Nanotechnology, vol. 8, no. 5, pp. 2472-2474, 2008.

[12] M. Reibold, P. Paufler, A. A. Levin, W. Kochmann, N. Pätzke, and D. C. Meyer, "Materials: carbon nanotubes in an ancient Damascus sabre," Nature, vol. 444, no. 7117, p. 286, 2006.

[13] R. A. Brown, A. K. Kercher, T. H. Nguyen, D. C. Nagle, and W. P. Ball, "Production and characterization of synthetic wood chars for use as surrogates for natural sorbents," Organic Geochemistry, vol. 37, no. 3, pp. 321-333, 2006.

[14] A. K. Kercher and D. C. Nagle, "Monolithic activated carbon sheets from carbonized medium-density fiberboard," Carbon, vol. 41, no. 1, pp. 3-13, 2003.

[15] N. Tippayawong, N. Saengow, E. Chaiya, and N. Srisang, "Production of charcoal from woods and bamboo in a small natural draft carbonizer," International Journal of Energy Environmental, vol. 1, no. 5, pp. 911-918, 2010.

[16] W. S. L. Mok, M. J. Antal Jr., P. Szabo, G. Varhegyi, and B. Zelei, "Formation of charcoal from biomass in a sealed reactor," Industrial and Engineering Chemistry Research, vol. 31, no. 4, pp. 1162-1166, 1992.

[17] X. Xie, B. Goodell, D. Zhang et al., "Characterization of carbons derived from cellulose and lignin and their oxidative behavior," Bioresource Technology, vol. 100, no. 5, pp. 1797-1802, 2009.

[18] T. Zhang, W. P. Walawender, L. T. Fan, M. Fan, D. Daugaard, and R. C. Brown, "Preparation of activated carbon from forest and agricultural residues through $\mathrm{CO}_{2}$ activation," Chemical Engineering Journal, vol. 105, no. 1-2, pp. 53-59, 2004.

[19] D. Adinata, W. M. A. Wan Daud, and M. K. Aroua, "Preparation and characterization of activated carbon from palm shell by chemical activation with $\mathrm{K}_{2} \mathrm{CO}_{3}$," Bioresource Technology, vol. 98, no. 1, pp. 145-149, 2007.

[20] F. Zhang, H. Ma, J. Chen, G. D. Li, Y. Zhang, and J. S. Chen, "Preparation and gas storage of high surface area microporous carbon derived from biomass source cornstalks," Bioresource Technology, vol. 99, no. 11, pp. 4803-4808, 2008.

[21] F. Zhang, K. X. Wang, G. D. Li, and J. S. Chen, "Hierarchical porous carbon derived from rice straw for lithium ion batteries with high-rate performance," Electrochemistry Communications, vol. 11, no. 1, pp. 130-133, 2009.

[22] W. Ruland and B. Smarsly, "X-ray scattering of non-graphitic carbon: an improved method of evaluation," Journal of Applied Crystallography, vol. 35, no. 5, pp. 624-633, 2002. 

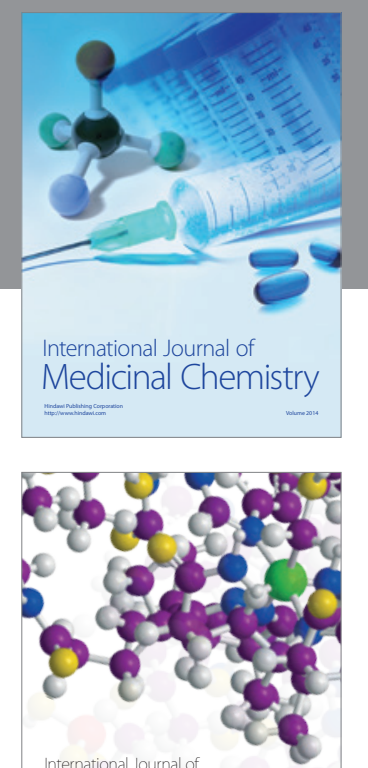

\section{Carbohydrate} Chemistry

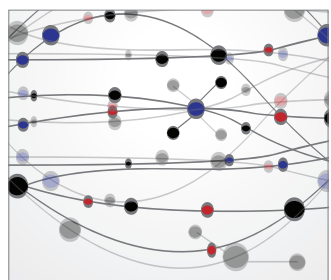

The Scientific World Journal
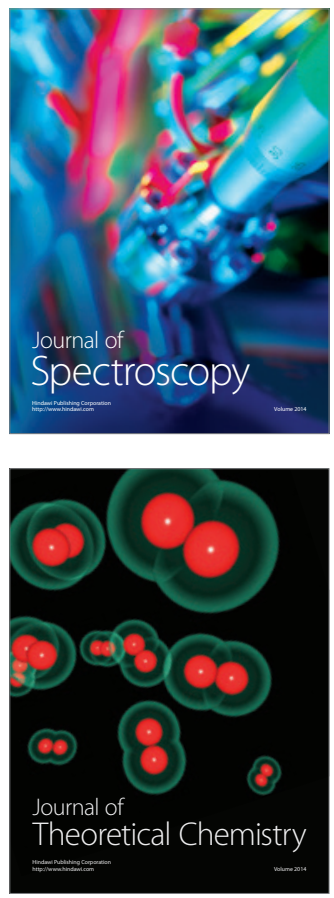
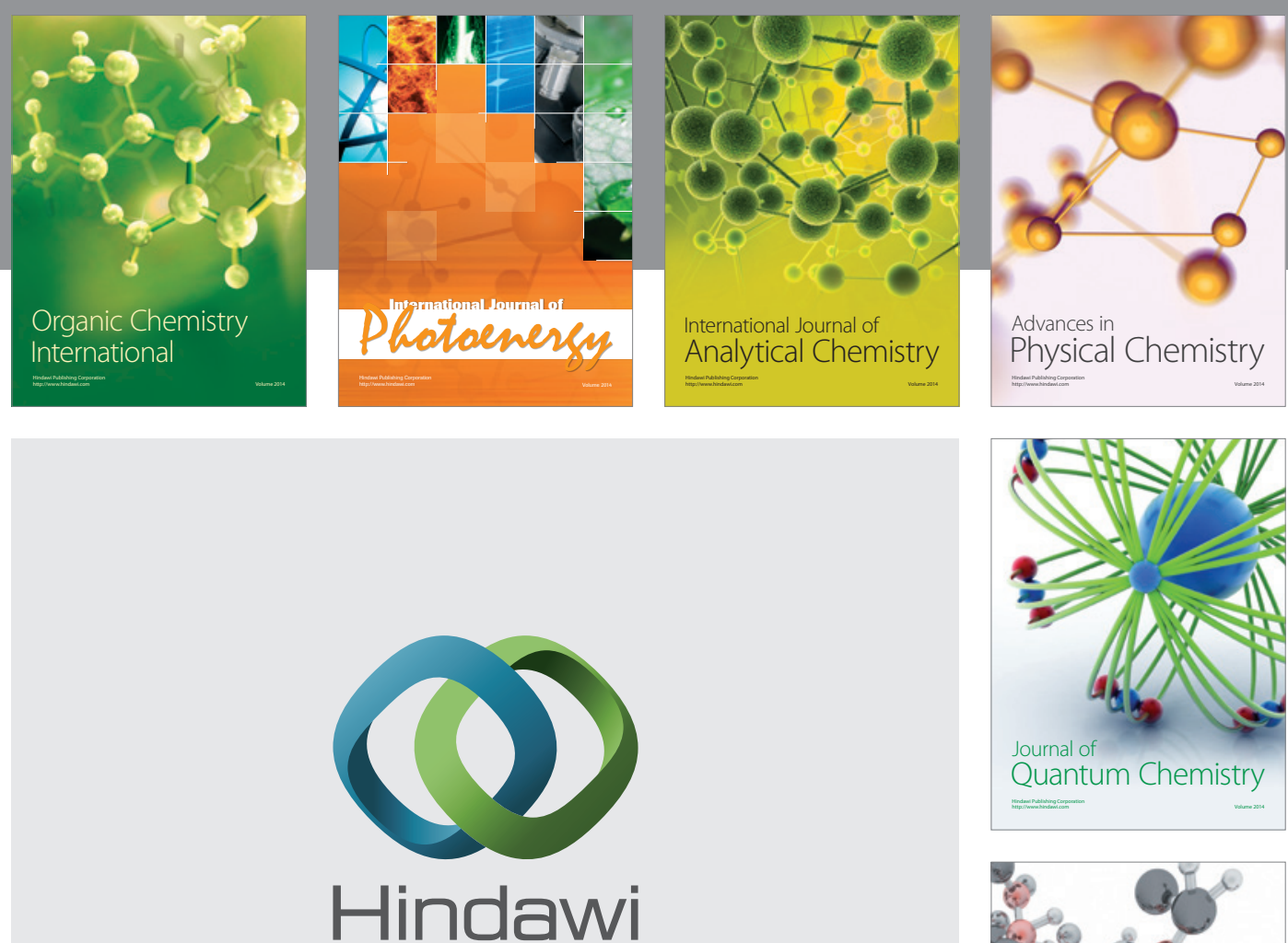

Submit your manuscripts at

http://www.hindawi.com

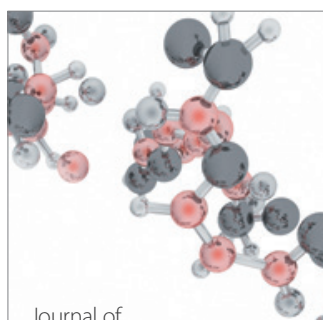

Analytical Methods

in Chemistry

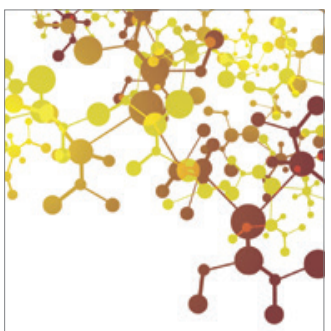

Journal of

Applied Chemistry

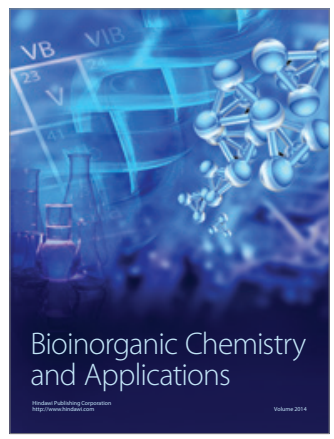

Inorganic Chemistry
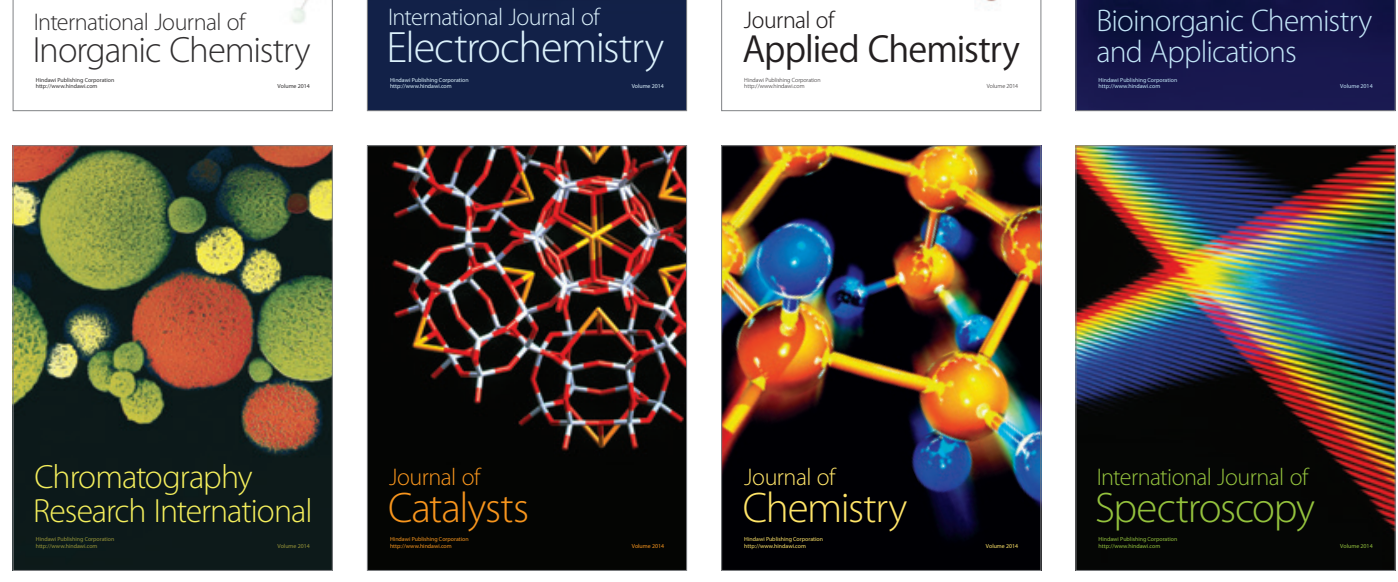